\title{
探索氟代碳酸乙烯酯添加剂对钠离子电池正极的影响
}

\author{
刘忠范 \\ 北京大学化学与分子工程学院, 北京 100871
}

\section{Insight into Effects of Fluoroethylene Carbonate Additive on the Cathode in Sodium Ion Batteries}

\section{LIU Zhongfan}

College of Chemistry and Molecular Engineering, Peking University, Beijing 100871, P. R. China. Email: zfliu@pku.edu.cn.

Published online: March 6, 2019.

储能技术已成为制约绿色新能源大规模开发 利用的瓶颈技术，作为便携式设备储能领域最受 欢迎的高能量密度锂离子二次电池因受限于锂资 源储量有限, 难以在新能源大规模储能市场中得 以可持续发展 ${ }^{1}$ 。因此, 寻找可替代锂离子电池的 二次电池成为一种必然发展趋势。钠与锂具有相 似物理化学性能, 且其储量丰富, 因此近几年钠离 子电池成为大规模储能市场的研究热点 2,3 。然而 受限于大的钠离子脱嵌带来的体积变化等原因, 钠离子电池的循环寿命与实际应用还有一定距离, 近年来领域内很多研究者致力于提高钠离子电池 的循环稳定性 4,5 。在电解液中加添加剂已在锂离 子电池中被证明是一种有效的提高电池循环稳定 性的重要方法 6 。氟代碳酸乙烯酯(FEC)作为一种 电解液添加剂, 具有较低的最低未被占据分子轨 道(LUMO) 能量, 易优先于其他电解液溶剂被还 原, 通常被认为是很好的负极成膜添加剂, 在锂离 子电池中得到广泛应用 7 , 也在钠离子电池中被证 明对钠负极具有很好的成膜作用 ${ }^{8}$, 然而, FEC对 于钠离子电池正极的影响(有害或有益)尚未被研 究过。鉴于此, 中国科学院苏州纳米技术与纳米仿 生研究所陈立桅、沈炎宾等人以FEC对钠离子电 池正极材料的影响为切入点, 深入研究了 FEC对 于层状钠离子正极材料 $\mathrm{P} 2-\mathrm{Na}_{x} \mathrm{Co}_{0.7} \mathrm{Mn}_{0.3} \mathrm{O}_{2}$ 的影 响。

该工作已在物理化学学报上在线发表 (doi: 10.3866/PKU.WHXB201811033) ${ }^{9}$ 。该工作结合电
化学, 形貌分析, 化学成分表征, 原位结构分析等 方法研究了FEC添加剂在钠离子电池中的作用。作 者发现适量的FEC添加剂不仅可以显著抑制电解 液溶剂 $\mathrm{PC}$ 的分解, 而且会在正极上形成一层富 $\mathrm{NaF}$ 的保护层, 提高循环过程中正极晶格结构的稳 定性, 从而提高电池的循环稳定性。密度泛函理论 (DFT)计算表明, FEC之所以能在正极上形成保护 层, 可能与其容易在正极界面与钠盐阴离子 $\mathrm{ClO}_{4}^{-}$ 结合反应有关。该工作为对设计及开发新的二次 电池电解液添加剂起到了很好的启发作用。

\section{References}

(1) Etacheri, V.; Marom, R.; Elazari, R.; Salitra, G.; Aurbach, D. Energy Environ. Sci. 2011, 4, 3243. doi: 10.1039/c1ee01598b

(2) Hong, S. Y.; Kim, Y.; Park, Y.; Choi, A.; Choi, N. S.; Lee, K. T. Energy Environ. Sci. 2013, 6, 2067. doi: 10.1039/c3ee40811f

(3) Palomares, V.; Serras, P.; Villaluenga, I.; Hueso, K. B.; CarreteroGonzalez, J.; Rojo, T. Energy Environ. Sci. 2012, 5, 5884. doi: $10.1039 / \mathrm{c} 2 \mathrm{ee} 02781 \mathrm{j}$

(4) Cao, Y.; Xiao, L.; Wang, W.; Choi, D.; Nie, Z.; Yu, J.; Saraf, L.V.; Yang, Z.; Liu, J. Adv. Mater. 2012, 24, 1205. doi: 10.1002/adm a.201100904

(5) Yabuuchi, N.;Hara, R.; Kajiyama, M.; Kubota, K.; Ishigaki, T.; Hoshikawa, A.; Komaba, S. Adv. Energy Mater. 2014, 4, 1301453. doi: 10.1002/aenm.201301453

(6) Lee; Y., J., Kim, H., Kang, K. Choi, N. S. J. Power Sources 2016, 320, 49. doi: 10.1016/j.jpowsour.2016.04.070 
(7) Zhang, X.; Cheng, X.; Chen, X.; Yan, C.; Zhang, Q. Adv. Funct. Mater. 2017, 27, 1605989. doi: 10.1002/adfm.201605989

(8) Komaba, S.; Ishikawa, T.; Yabuuchi, N. ACS Appl. Mater. Interfaces 2011, 3, 4165. doi: 10.1021/am200973k
(9) Cheng, Z.; Mao, Y.; Dong, Q.; Jin, F.; Shen, Y.; Chen, L. Acta Phys. -Chim. Sin. 2019, 35 (8), 868. [程振杰, 毛亚云, 董庆雨, 金峰, 沈炎宾, 陈立桅. 物理化学学报, 2019, 35 (8), 868.] doi: 10.3866/PKU.WHXB201811033 